\title{
Article \\ Heterodimer Formation of the Homodimeric ABC Transporter OpuA
}

\author{
Patricia Alvarez-Sieiro ${ }^{\dagger}$, Hendrik R. Sikkema ${ }^{\dagger}+\mathbb{D}$ and Bert Poolman ${ }^{*}$ \\ Department of Biochemistry, Groningen Biomolecular Sciences and Biotechnology Institute, \\ University of Groningen, Nijenborgh 4, 9747 AG Groningen, The Netherlands; p.alvarez.sieiro@rug.nl (P.A.-S.); \\ hendriksikkema@gmail.com (H.R.S.) \\ * Correspondence: b.poolman@rug.nl \\ t These authors contributed equally to this work.
}

check for updates

Citation: Alvarez-Sieiro, P.; Sikkema, H.R.; Poolman, B. Heterodimer Formation of the Homodimeric ABC Transporter OpuA. Int. J. Mol. Sci. 2021, 22, 5912. https://doi.org/ $10.3390 /$ ijms 22115912

Academic Editors: Stathis Frillingos and Maria Botou

Received: 29 April 2021

Accepted: 28 May 2021

Published: 31 May 2021

Publisher's Note: MDPI stays neutral with regard to jurisdictional claims in published maps and institutional affiliations.

Copyright: (c) 2021 by the authors. Licensee MDPI, Basel, Switzerland. This article is an open access article distributed under the terms and conditions of the Creative Commons Attribution (CC BY) license (https:/ / creativecommons.org/licenses/by/ $4.0 /)$.

\begin{abstract}
Many proteins have a multimeric structure and are composed of two or more identical subunits. While this can be advantageous for the host organism, it can be a challenge when targeting specific residues in biochemical analyses. In vitro splitting and re-dimerization to circumvent this problem is a tedious process that requires stable proteins. We present an in vivo approach to transform homodimeric proteins into apparent heterodimers, which then can be purified using two-step affinitytag purification. This opens the door to both practical applications such as SmFRET to probe the conformational dynamics of homooligomeric proteins and fundamental research into the mechanism of protein multimerization, which is largely unexplored for membrane proteins. We show that expression conditions are key for the formation of heterodimers and that the order of the differential purification and reconstitution of the protein into nanodiscs is important for a functional ABCtransporter complex.
\end{abstract}

Keywords: ABC-transporter; OpuA; homo- and heterodimeric complexes; affinity purification; mechanism of multimerization; membrane protein; nanodisc reconstitution

\section{Introduction}

Most proteins exist as multimeric complexes, in bacteria often as symmetric homomers with identical subunits derived from the same gene (as is evident for e.g., ATP-binding cassette transporters), whereas in (higher) eukaryotes, complex heteromers or proteins with domains that fused and evolved independently are relatively more common [1,2]. In general, multimerization is a feature that confers advantages for the cell as described by $[1,3]$. First, large complexes have a smaller surface area-to-volume ratio, which increases stability and may reduce protein denaturation and promiscuous interactions. Second, complexes consisting of multiple small proteins are easier to fold than single-chain complexes of similar size. Moreover, big multimeric complexes not only increase the chance for allosteric modulation of protein activity but also the frequency of substrate encounter. In addition, homomultimeric proteins have additional advantages as error control in synthesis and more efficient use of genomic space compared to heteromultimeric or monomeric complexes, thereby saving metabolic energy [1,3-6].

However, the assembly of multimers is not as trivial, as they consist of individually translated protein chains. When do the subunits assemble? How do they find one another? The answer to these questions is diverse, as highlighted in recent reviews [7-9]. Among the assembly scenarios, we can distinguish post- and co-translational assembly. In the former, the proteins assemble as full subunits, in the latter, they assemble during the translation process of at least one chain, see [10] for a review. Naturally, both scenarios require the subunits to be in close proximity. The proximity or local concentration of the subunits is affected by diffusion and the location of their synthesis in the cell. In bacteria, the subunits of multimeric proteins are typically expressed from the same operon and thus formed in 
a given order. If the same subunit is needed more than once, it may still originate from the same operon transcript (polysomal synthesis) but will be formed at a later time [11]. Alternatively, it may be formed from another transcript elsewhere in the cell, and in that case, the subunits will have to diffuse further through the membrane or cytoplasm to find each other [12]. The successful assembly of a multimeric complex will also depend on the concentration of the components and their affinity for each other [12,13]. An additional layer of complexity comes from these factors not being the same for membrane proteins and soluble proteins, as the diffusion of membrane proteins is two to three orders of magnitude slower and occurs in a 2D space compared to faster diffusion in 3D for soluble proteins, yet the orientational restriction of proteins in the membrane offers an advantage for their assembly ([14], see also the Discussion section). Furthermore, the folding, which is dominated by hydrophobic interactions for soluble proteins, is very different in membrane proteins $[7,8,15]$.

Studying homomultimeric proteins can be a challenge, as many tools in chemical biology and biochemistry rely on the modification of cysteine residues and or incorporated non-natural amino acids. In homomultimers, any mutation made in one subunit will be replicated in the other(s), which can be problematic if one aims to label specific sites with probes for fluorescence (e.g., single-molecule Förster Resonance Energy Transfer, smFRET), electron spin resonance (e.g., Double Electron-Electron Resonance measurements, DEER) or other probe-based assays. As an example, for smFRET, a fluorescence donor and acceptor need to be introduced at specific sites, which is often done by introducing Cys or non-natural amino acids that can be labeled with the appropriate probe [16]. However, in homodimeric proteins for example, the introduction of two mutations already introduces four sites for labeling, which significantly complicates the spectroscopy. In other cases [17], a single point mutation in one protomer may be required to answer important scientific questions.

To circumvent the problem, one could purify the protein, separate the subunits, and subsequently mix differentially labeled subunits and reassemble the protein complex. We have previously taken this approach in the study of the ATP-binding cassette (ABC) transporter OpuA from Lactococcus lactis [18]. OpuA is a homodimeric membrane protein composed of two membrane subunits (OpuABC) and two nucleotide-binding subunits (OpuAA). OpuABC comprises the transmembrane domain (TMD), which is surrounded by a scaffold and connected to the extracytoplasmic substrate-binding domain (SBD). The OpuA complex in the detergent-solubilized state disassembles into two OpuABC and two OpuAA subunits when the glycerol concentration falls below $15-20 \%(v / v)$, but the dissociation of the complex is reversible. In this way, we were able to create apparent heterodimeric complexes in which one of the transmembrane subunits was engineered and the other one not. Similar methods have been used for e.g., the membrane proteins GltPh, VcINDY, and BetP $[19,20]$. However, this approach is not generally applicable, especially for proteins that are not stable in a detergent environment or for which the monomers cannot be separated. Therefore, we sought for a more generic method to specifically alter one subunit of homomultimeric protein complexes prior to assembly.

Here, we present a genetic approach to form apparent heteromers from homomultimeric proteins. We reasoned that it should be possible to form apparent heteromultimeric complexes of the OpuABC subunit by duplicating the opuABC gene and making constructs in which one of the subunits has a metal affinity and the other has a streptavidin tag for purification, named OpuABC-H and OpuABC-S, respectively. In vivo, the following protein complexes will form: (OpuAA $)_{2}-(\mathrm{OpuABC}-\mathrm{H})_{2},(\mathrm{OpuAA})_{2}-(\mathrm{OpuABC}-\mathrm{S})_{2}$ and (OpuAA $)_{2}-\mathrm{OpuABC}-\mathrm{H}-\mathrm{OpuABC}-\mathrm{S}$, theoretically in a ratio of 1:1:2 if the OpuABC-H and OpuABC-S subunits are formed in equal amounts and have equal probability of assembling into a functional complex (Figure 1). Differential affinity chromatography can subsequently be used to enrich for (OpuAA) $)_{2}-\mathrm{OpuABC}-\mathrm{H}-\mathrm{OpuABC}-\mathrm{S}$. 


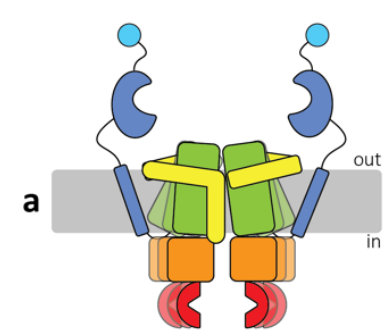
HOMODIMER

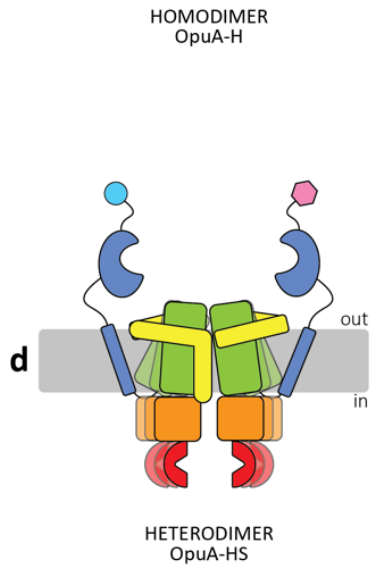

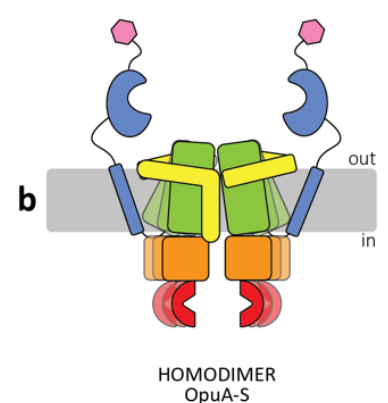

OpuA-S

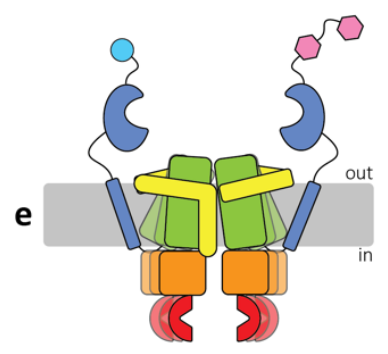

HETERODIMER
OpUA-HSS

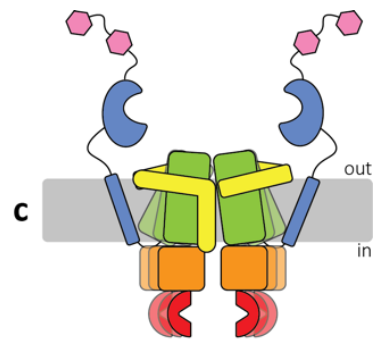

HOMODIMER OPUA-SS

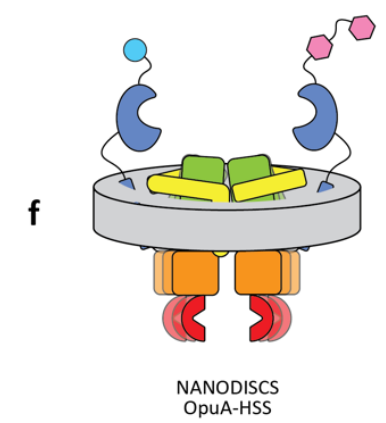

Figure 1. Schematic representation of various OpuA constructs used in this study. The wild-type transporter OpuA is composed of two OpuAA subunits, each carrying a tandem cystathionine- $\beta$ synthase (CBS) domain (red) and the ATP-binding domain (orange), and two OpuABC subunits, each carrying a transmembrane domain (TMD) (green), including the scaffold domain (yellow) and the substrate-binding domain (SBD) (blue). (a) Homodimeric OpuA-H, the wild-type OpuA, with a His ${ }_{6}{ }^{-}$ tag (cyan circle) linked to the SBD; (b) Homodimeric OpuA-S, OpuA tagged with a StrepII-tag (pink hexagon) linked to the SBD; (c) Homodimeric OpuA-SS, OpuA containing a TwinStrepII-affinity tag (double pink hexagon) linked to the SBD; (d) Heterodimeric OpuA-HS, OpuA containing a His ${ }_{6}$-tag in one SBD and a StrepII-tag in the other SBD; (e) Heterodimeric OpuA-HSS, OpuA composed of one SBD tagged with His $_{6}$-tag and another one with TwinStrepII-tag; (f) Schematic representation of OpuA-HSS in nanodiscs; lipids and MSP1D1 scaffolding protein are shown as grey discs.

We found that nanodisc reconstitution plays a decisive role in the successful purification and functionality of the heterodimeric complex. Nanodiscs have become an essential tool for structural and functional studies of membrane proteins. They provide a native-like phospholipid bilayer environment, allowing the stability and functionality of membrane proteins [21,22]. In this paper, we present the different strategies to form apparent heterooligomeric OpuA complexes in L. lactis and the methodology to purify the proteins.

\section{Results}

We first constructed a series of expression plasmids for L. lactis and evaluated the expression and purification of homodimeric OpuA variants with three different affinity tags (Figure 2a): His ${ }_{6}$-tag, StrepII-tag, and TwinStrepII-tag. Each of the tags is present at the $\mathrm{C}$-terminus of the OpuABC subunit. The genes are present in an operon in the order opuAA$о p u A B C$, and they are cloned under the control of the tightly regulated nisin-inducible $p N i s A$ promoter, using the medium-copy number vectors $\mathrm{pNZ} 8048\left(\mathrm{Cm}^{\mathrm{Res}}\right.$, $\mathrm{pSH71}$ origin of replication) and pIL253 ( $\mathrm{Cm}^{\text {Res }}$, pSH71 origin of replication). The pNZ8048 vector has a so-called pSH71 rolling-circle type of replication [23], whereas the pAM $\beta 1$-derived vector pIL253 is a theta-replicating plasmid [24]. Both vectors are compatible with each other and thus can be used for the co-expression of proteins in the same host [25]. 
a
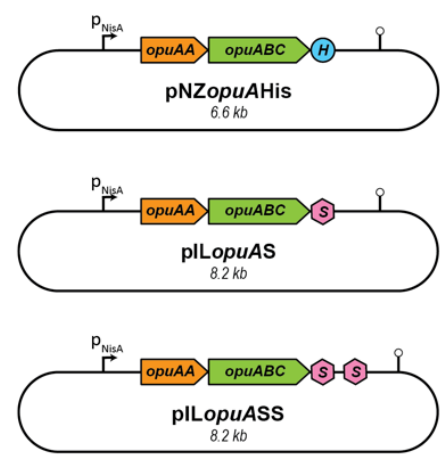

C

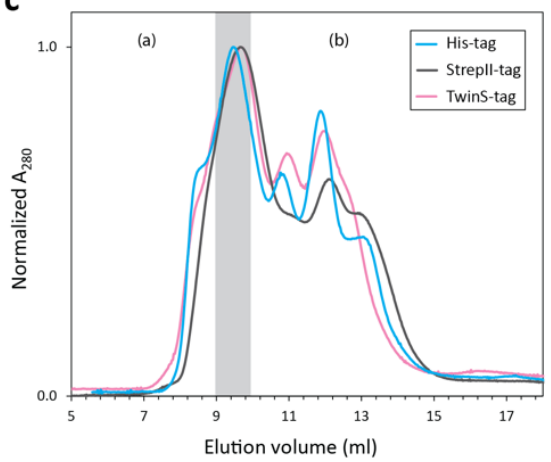

b

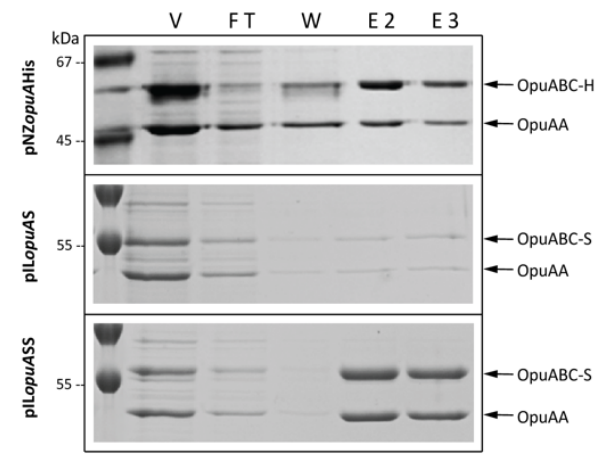

d
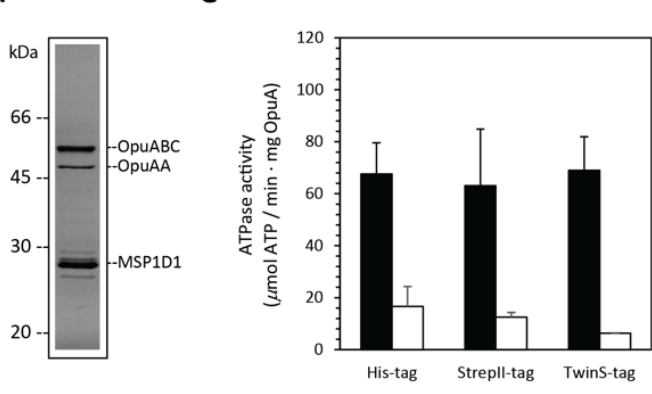

Figure 2. Characterization of three differently tagged homodimeric OpuA constructs. (a) Schematic plasmid maps of the expression vectors. OpuAA, gene encoding the ATPase subunit and CBS domains of OpuA; opuABC, gene encoding the TMD and SBD of OpuA; $p N i s A$, nisin-inducible promoter; $\mathrm{H}$, His $_{6}$-tag; S, StrepII-tag; double S, TwinStreptII-tag; bent arrows and lollipop symbols represent the promoters and terminators, respectively. (b) SDS-PAGE analysis ( $12.5 \%$ polyacrylamide) of affinity purifications of the three homodimeric OpuA constructs (OpuA-H, OpuA-S, and OpuA-SS). The indicated proteins were purified from crude membrane extracts as explained in the text. The fractions tested were membrane vesicles (V), column flow through (FT), wash (W), and elution fractions (E). (c) Size exclusion chromatography profiles of homodimeric OpuA nanodiscs, using a Superdex 200 increase 10/300 GL column. The chromatograms were normalized to the highest peak. The peak fractions used for further analysis are indicated by the gray shading. (a) and (b) represent the peak fractions of aggregated and empty nanodiscs, respectively. (d) Typical peak fraction of nanodiscs analyzed by $12.5 \%$ SDS-PAGE, showing the presence of OpuAA, OpuABC, and the scaffold protein MSP1D1. (e) ATPase activity in the presence (black bars) and absence (white bars) of $62 \mu \mathrm{M}$ substrate (glycine betaine). Error bars represent the standard deviation of independent triplicates.

\subsection{Verification of Activity with Different Affinity Tags}

To avoid recombination with genomic opuA genes, the plasmids were transformed into L. lactis Opu401, an opuA deletion strain that was derived from L. lactis NZ9000 [26]. SDS-PAGE analysis shows the successful purification of OpuA with each of the three different affinity tags. Both subunits (OpuAA and OpuABC) are present in an approximate 1:1 ratio (Figure 2b) [18,26-28]. We obtained approximately $110 \mathrm{mg}$ of membrane vesicles per $2 \mathrm{~L}$ culture for each of the three strains. However, the OpuA yield was very different depending on the affinity tag used; the His 6 -tag was the most efficient with a yield of $\approx 18 \%$ of purified OpuA (determined by integrating the A280 signal of product peak in the gel-filtration chromatogram; in the cases where there was no SEC run of the final product, a nanodrop was used to determine the A280 signal of the elution) per $\mathrm{mg}$ of total vesicle protein (determined by BCA assay), followed by TwinStrepII-tag with a $\approx 9 \%$ yield and StrepII-tag with $\mathrm{a} \approx 2.5 \%$ yield. The ATP hydrolysis activities of homodimeric OpuA with His $_{6}$-tag, StrepII-tag, or TwinStrepII-tag were verified in the nanodisc environment. OpuA was reconstituted in MSP1D1 nanodiscs with the lipid composition of $38 \mathrm{~mol} \%$ DOPG 
(1,2-dioleoyl-sn-glycero-3-phosphatidylglycerol), $12 \mathrm{~mol} \%$ DOPC (1,2-dioleoyl-sn-glycero-3phosphatidylcholine) plus $50 \mathrm{~mol} \%$ DOPE (1,2-dioleoyl-sn-glycero-3-phos-phatidylethanolamine) and a reconstitution ratio of OpuA/lipids/MSP1D1 of 1:20:2000 [27].

The size exclusion chromatography profiles of the three homodimeric OpuA complexes are very similar (Figure 2c). SDS-PAGE analysis (Figure 2d) illustrates the presence of the OpuAA ( $47 \mathrm{kDa}$ ) and OpuABC (63 kDa) subunits and the scaffold protein MSP1D1 (25 kDa). The ATPase activity with and without the substrate of OpuA, glycine betaine, was determined using a coupled enzyme assay consisting of limiting amounts of OpuA in nanodiscs and an excess of pyruvate kinase plus lactate dehydrogenase activity. The different affinity tags did not significantly influence the glycine betaine-dependent hydrolysis of ATP by OpuA (Figure 2e).

\subsection{Heterodimer Formation}

Next, we transformed plasmid pNZopuAHis in combination with either pILopuAS or pILopuASS into L. lactis Opu401 to obtain heterodimers with different affinity tags. Theoretically, this approach can yield three different species: $\mathrm{His}_{6}$-tagged homodimeric OpuA (OpuA-H), Strep-tagged homodimeric OpuA (OpuA-S; OpuA-SS), and heterodimeric OpuA containing both a $\mathrm{His}_{6}$ and a Strep-tagged subunit (OpuA-HS; OpuAHSS; Figure 3a). To solely select and purify the desired heterodimeric protein, we apply a two-step affinity chromatography (summarized in Figure 3b,c).

The initial protocol to obtain the hetero OpuA-HS mutant was based on an $\mathrm{Ni}^{2+}$ Sepharose purification to retain all $\mathrm{His}_{6}$-tagged complexes and thus remove Strep-tagged homodimers (OpuA-S) followed by a Strep-tactin purification to retain the Strep-tagged complexes (heterodimers) and remove $\mathrm{His}_{6}$-tagged homodimers $(\mathrm{OpuA}-\mathrm{H})$ or vice versa. Finally, size exclusion chromatography was used for further purification and quality control (degree of monodispersity). However, little to no protein was obtained after the two purification steps; therefore, either the heterodimeric species did not form or it was lost in the purification process.

\subsection{Heterologous Recombination}

The pNZopuAHis and pILopuAS vectors are compatible and have different antibiotic markers, but both carry homologous opuA sequences (Figure 2a) that may recombine and jeopardize heterodimer formation. RecA is the major protein involved in homologous recombination and DNA repair in L. lactis [29-31]. Therefore, we constructed an L. lactis Opu401 $\Delta r e c A$ strain (Table 1). We transformed both plasmids and applied the same purification protocol as described above, but the yield of heterodimeric OpuA was still negligible (data not shown), suggesting that RecA homologous recombination is not a main problem.

\subsection{Optimization of Induction}

The overproduction of proteins can activate stress responses, which has been shown to influence protein expression in L. lactis [32] and other (micro)organisms [33-35]. One strategy to minimize this effect is to slow down the protein production by decreasing the amount of inducer or lowering the induction temperature. To optimize the induction conditions, we performed small-scale $(50 \mathrm{~mL})$ induction tests. After reaching a cell density of $\mathrm{OD}_{600}=0.5$, we induced with $0.05 \%, 0.02 \%, 0.01 \%$ or $0.002 \%(v / v)$ of culture supernatant of the nisin A-producing strain L. lactis NZ9700 [36] (hereafter referred to as nisin A*), and the temperature during induction was either kept at $30^{\circ} \mathrm{C}$ or lowered to $21^{\circ} \mathrm{C}$ for 2, 4, or $8 \mathrm{~h}$ (Figure 4a). For each condition, membrane vesicles were obtained, and OpuA was purified by a single $\mathrm{Ni}^{2+}$-Sepharose purification step, obtaining a mixture of His $_{6}$-tagged homodimers (OpuA-H) and heterodimers (OpuA-HS) (Figure 4b). Then, the fraction of OpuA-HS was quantified by Western blotting with monoclonal antibodies raised against the StrepII-tag. Indeed, a lower induction temperature led to higher amounts of heterodimer, albeit at the expense of cell biomass from which to purify protein. 
a Expression and production of OpuA
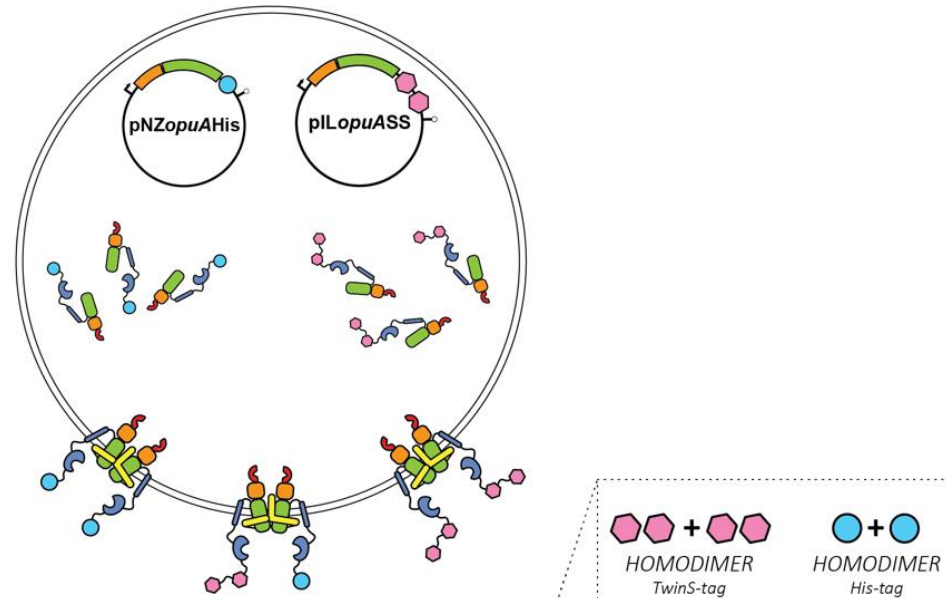

$00+0$

HETERODIMER Twins-tag + His-tag

b Solubilization of membrane vesicles

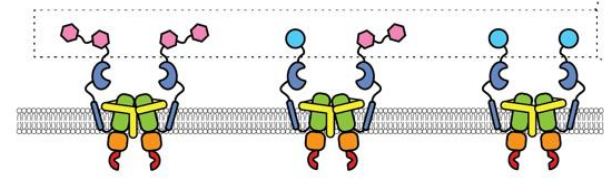

C Purification
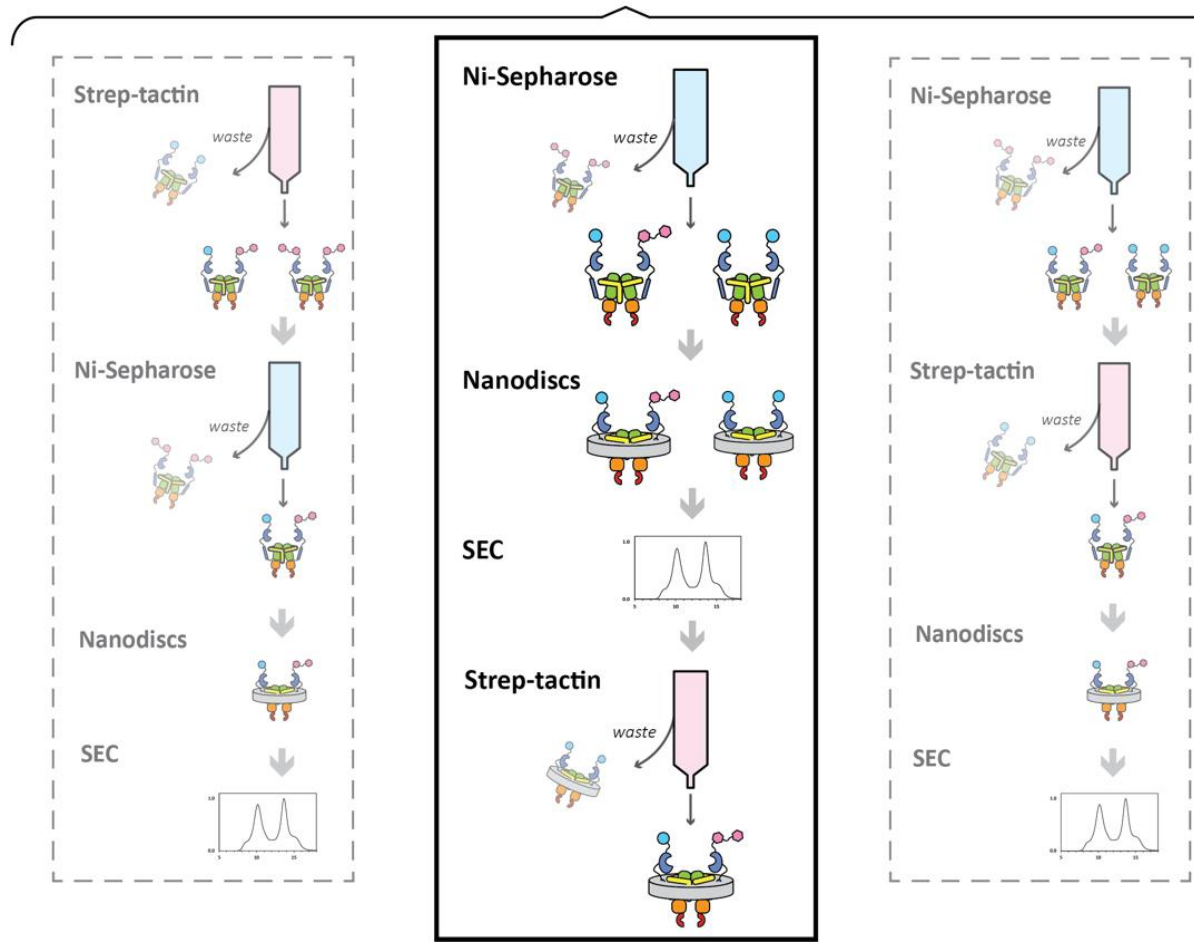

Figure 3. Schematic of the purification of the heterodimeric OpuA. (a) L. lactis Opu401 strain carrying plasmids pNZopuAHis and pILopuASS was grown in glucose-M17 broth at $30^{\circ} \mathrm{C}$ and the genes were expressed with $0.05 \%(v / v)$ nisin $A^{*}$ at $21^{\circ} \mathrm{C}$ for $4 \mathrm{~h}$. Three possible OpuA variants are formed in the cell: OpuA-H, OpuA-SS, and OpuA-HSS. (b) Solubilization of membrane vesicles were carried out as described in the Methods section. (c) Three different purification strategies were tested by varying the order of the different steps. The central bold lined square highlights the most efficient protocol. 
a
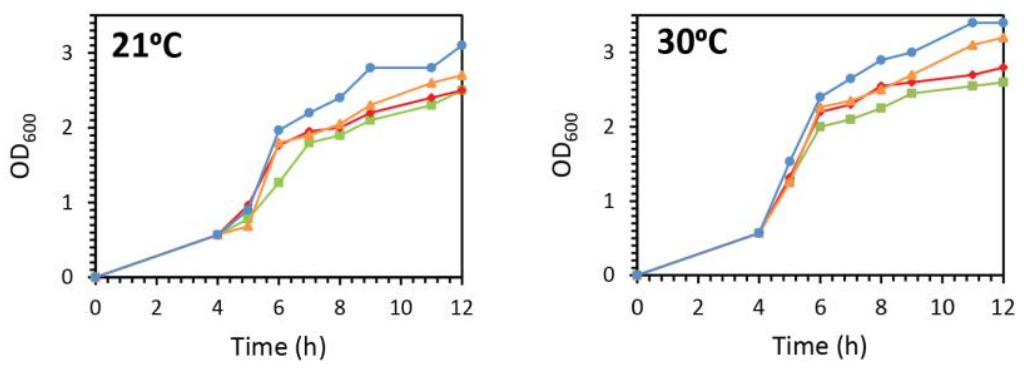

b

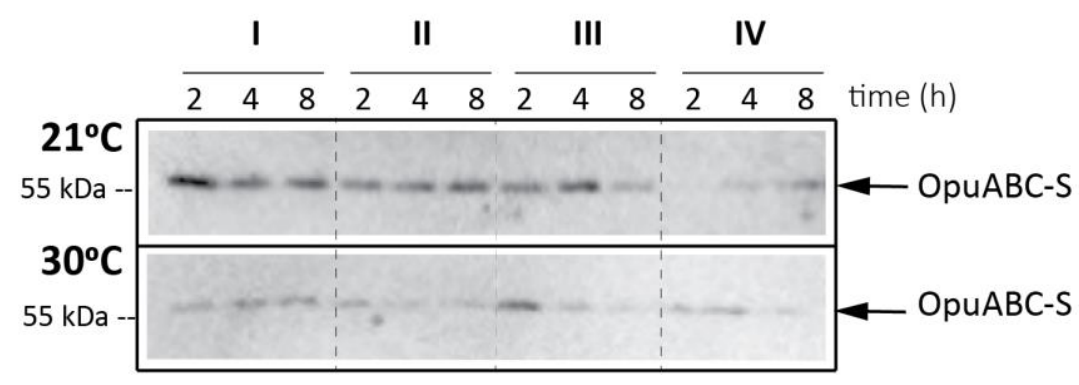

Figure 4. Optimization of the heterodimer formation under different induction conditions. (a) $L$. lactis Opu401 strain, harboring plasmids pILopuAS and pNZopuAHis, was propagated at $30{ }^{\circ} \mathrm{C}$ in glucose-M17 broth as described in the text. When cultures reached an $\mathrm{OD}_{600}$ of 0.5 , they were induced at four different nisin $\mathrm{A}^{*}$ concentrations: $0.05 \%$ (green square), $0.02 \%$ (red diamond), $0.01 \%$ (orange triangle), and $0.002 \%$ (blue circle). Then, cultures $(50 \mathrm{~mL}$ ) were incubated at two different temperatures, 21 or $30^{\circ} \mathrm{C}$, and induction times of 2, 4, and $8 \mathrm{~h}$ were tested. (b) Membrane vesicles were obtained, and proteins were purified with $\mathrm{Ni}^{2+}$-Sepharose resin. To check the presence of the heterodimeric OpuA variant, final elution fractions were analyzed by Western blot analysis, using monoclonal antibodies directed against the StrepII-tag. The Roman numerals indicate the different nisin concentrations: $0.05 \%$ (I), $0.02 \%$ (II), $0.01 \%$ (III), and $0.002 \%$ (IV).

Based on the induction test, we selected two conditions for further experiments: Growth at $30{ }^{\circ} \mathrm{C}$, followed by (i) induction at $21^{\circ} \mathrm{C}$ with $0.05 \%(v / v)$ of nisin $\mathrm{A}^{*}$ for $2 \mathrm{~h}$ and (ii) induction at $21^{\circ} \mathrm{C}$ with $0.01 \%(v / v)$ nisin $\mathrm{A}^{*}$ for $4 \mathrm{~h}$. Large-scale $2 \mathrm{~L}$ cultures were induced, and membrane vesicles were prepared as described in the Methods section. The decrease in the temperature during induction reduced the final membrane vesicle protein yield from 55 to $37.5 \mathrm{mg} / \mathrm{L}$, but the amount of heterodimeric OpuA relative to the amount of membrane vesicles was increased by at least 2 -fold. The purification of OpuA-HS from the best expression conditions $\left(0.01 \%\right.$ nisin $\left.\mathrm{A}^{*} ; 21{ }^{\circ} \mathrm{C} ; 4 \mathrm{~h}\right)$ was analyzed by SDS-PAGE and Western blotting (Figure 5). We also observed that the yield of heterodimeric OpuA is dependent on the order of the purification steps. Strep-tactin purification followed by $\mathrm{Ni}^{2+}$ Sepharose purification yielded a recovery of $0.008 \%$ (6.4 $\mu \mathrm{g}$ of heterodimer from $75 \mathrm{mg}$ of vesicle protein). $\mathrm{Ni}^{2+}$-Sepharose purification followed by Strep-tactin purification yielded a recovery of $0.12 \%$ ( $88 \mu \mathrm{g}$ of heterodimer from $75 \mathrm{mg}$ of vesicle protein). Despite the improvements in the conditions, the low efficiency and recovery yield prohibited further studies, e.g., reconstitution of heterodimeric OpuA for functional analyses. 


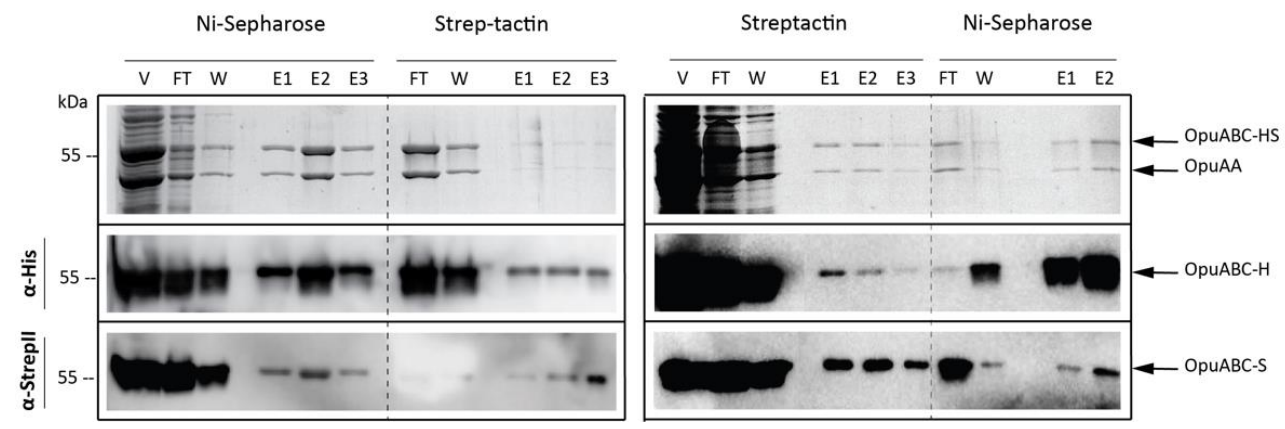

Figure 5. SDS-PAGE (upper panel) and Western blot (two lower panels) analysis of the two-step affinity purification of OpuA. L. lactis Opu401 carrying plasmids pNZopuAHis plus pILopuAS was grown and induced under the following conditions $\left(0.01 \%\right.$ nisin $\mathrm{A}^{*} ; 21{ }^{\circ} \mathrm{C}$ during induction; $4 \mathrm{~h}$ of induction). Membrane vesicles were obtained as described in the Methods section, and after solubilization of the membranes with $0.5 \%(w / v)$ DDM, the lysate was subjected to two affinity purification steps: $\mathrm{Ni}^{2+}$-Sepharose followed by Strep-tactin (left panel) or vice versa (right panel). The following fractions were tested: vesicles (V), flow through (FT), wash (W), and elution fractions (E). Monoclonal antibodies directed against the His $_{6}$-tag and StrepII-tag were used, as indicated on the left side of the immunoblots.

\subsection{TwinStrepII-Tag}

Fusion proteins containing two copies of StrepII-tag, i.e., TwinStrepII-tag, have higher affinity for Strep-tactin compared to those with only a single StrepII-tag, thus allowing more efficient protein purification, as we showed for the homodimeric complex (Figure 2B). To increase the yield of heterodimeric OpuA, we switched from pILopuAS to pILopuASS, which contains the C-terminal TwinStrepII-tag sequence. After two steps of purification, the yield of heterodimeric OpuA was indeed higher and increased to approximately $0.4 \%$ recovery $(80 \mu \mathrm{g}$ of heterodimer from $19 \mathrm{mg}$ of vesicle protein). The four times higher recovery yield now allowed for continuation with further experiments. Moreover, the TwinStrepII-tagged OpuA subunit (OpuABC-SS) not only allowed obtaining a higher protein yield, but this subunit also migrates differently on SDS-PAA gels and clear separation from the $\mathrm{His}_{6}$-tagged subunit (OpuABC-H) (see Section 2.7), allowing easy visualization of the extent of heterodimer formation on SDS-PAGE. Heterodimeric OpuA-HSS was reconstituted into nanodiscs; however, SDS-PAGE analysis of SEC chromatograms profiles showed dissociation of the nucleotide-binding domain (OpuAA) from the OpuA complex, as has been shown before [18], explaining the lack of ATP hydrolysis activity.

\subsection{Optimization of Reconstitution}

Two sequential affinity tag purifications require the protein to be stable in the detergent solubilized state for up to $12 \mathrm{~h}$, which is problematic for OpuA, as the complex readily dissociates, especially in low glycerol concentrations [18]. Therefore, we proceeded by performing the reconstitution in between the two purification steps. Thus, the OpuA complexes were purified by metal-affinity chromatography and then immediately incorporated into MSP1D1based nanodiscs, which yields a population of homodimeric OpuA-H and heterodimeric OpuA-HSS nanodiscs. Within the membrane environment of the nanodiscs, OpuA is much more stable, and the glycerol concentration can be lowered to $4 \%$, which increased the Streptactin purification efficiency. Furthermore, to improve the quality of the OpuA nanodiscs, we varied the lipid/protein stoichiometry during the self-assembly process (Figure 6a). The fully assembled OpuA nanodiscs, with a diameter of roughly $10 \mathrm{~nm}$, elute between 9 and $10 \mathrm{~mL}$. The void peak around $8 \mathrm{~mL}$ contains liposome-like structures, and the peaks at higher elution volumes $(>11 \mathrm{~mL})$ are empty nanodiscs or belt protein structures, as determined previously [27,37]. We found that a combination of higher concentration of OpuA $(4.32 \mu \mathrm{M})$ and a ratio of OpuA/MSP1D1/lipids of 1:20:1000 yields a more separated peak fraction during size exclusion chromatography and a higher ATPase activity (Figure 6b). 
a

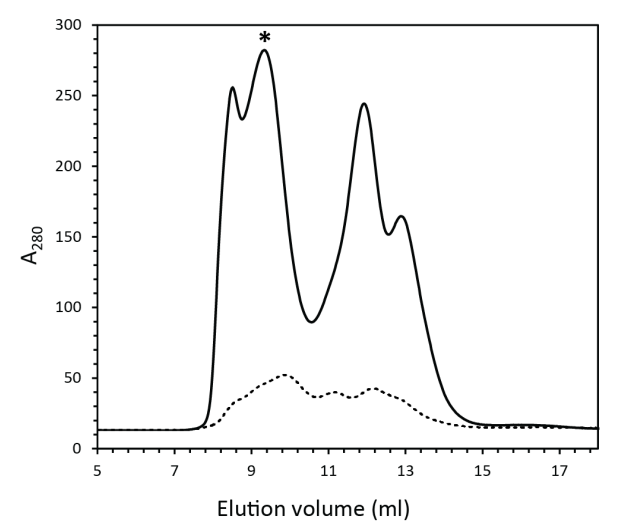

b

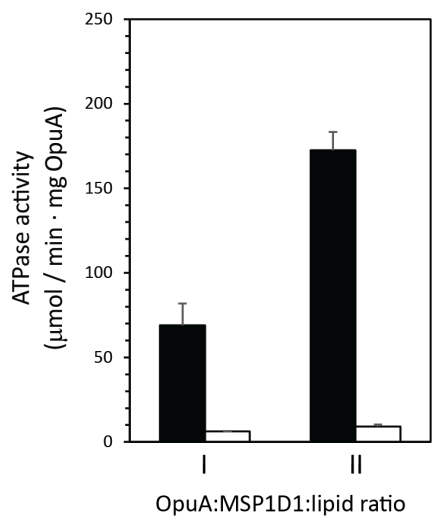

Figure 6. Optimization of OpuA reconstitution in nanodiscs. Homodimeric OpuA-SS was purified and reconstituted in nanodiscs formed at different molar ratios and concentrations. (a) Size exclusion chromatography profile of nanodiscs formed at a OpuA/MSP1D1/lipids ratio of 1:20:2000 (dotted line) and 1:20:1000 ratio (solid line); in the latter case, we used a six-times higher concentration of OpuA. Star represents the peak fraction with active OpuA-SS nanodiscs. We verified the dimeric state of OpuA in the peak fraction from the intensity of OpuAA, OpuABC, and MSP1D1 bands on SDS-PAA gels. (b) ATPase activity of OpuA-SS reconstituted in nanodiscs formed at a ratio of 1:20:2000 (I) and 1:20:1000 (II). Black and white bars represent activity in the presence and absence of $62 \mu \mathrm{M}$ glycine-betaine, respectively. Error bars represent the standard deviation of triplicates.

\subsection{Purification of the OpuA-HSS Heterodimer}

Cells were induced under optimal condition (growth and induction temperature of $21{ }^{\circ} \mathrm{C}, 4 \mathrm{~h}$ of induction with $0.01 \%$ nisin $\mathrm{A}^{*}$ ), and $24 \mathrm{mg}$ of membrane vesicles were subjected to $\mathrm{Ni}^{2+}-$ Sepharose purification, yielding a total of $3.8 \mathrm{mg}$ of $\mathrm{His}_{6}$-tagged homodimers and heterodimers (OpuA-H and OpuA-HS). This mixture was reconstituted into nanodiscs and purified by SEC. The chromatogram showed a well-separated peak fraction (Figure 7a), and the SDS-PAGE analysis showed a comparable intensity for the OpuAA and OpuABC subunits (Figure $7 \mathrm{~b}$ ). Next, the selected peak fraction was purified on a Strep-tactin resin, yielding a total of $50 \mu \mathrm{g}$ of heterodimeric OpuA in nanodiscs, which corresponds to a recovery of $0.2 \%$. Functionality of the heterodimeric OpuA-HSS protein was demonstrated by ATPase activity measurements (Figure 7c). We attribute the somewhat lower activity of the heterodimer, compared to similar amounts of homodimeric OpuA nanodiscs, to the loss of a fraction of the OpuAA subunit, as can be seen on SDS-PAGE gels (Figure 7b).

a

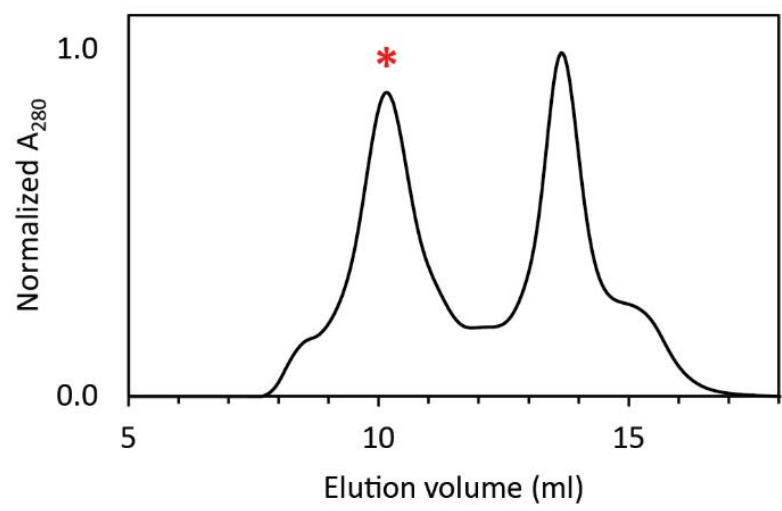

Figure 7. Cont. 


\section{b}

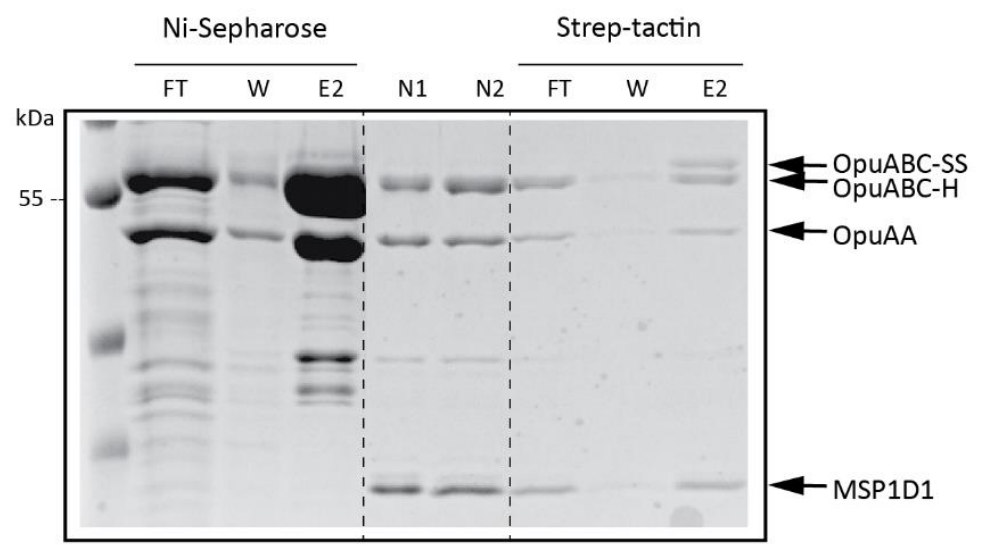

C

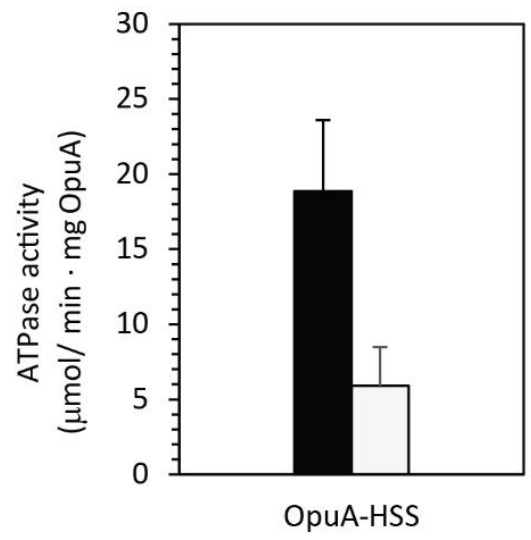

Figure 7. Purification and characterization of the heterodimeric OpuA-HSS. Membrane vesicles containing a mixture of OpuA-H, OpuA-SS, and OpuA-HSS were obtained as described in the Methods section and subjected to a series of purification steps: (i) $\mathrm{Ni}^{2+}$-sepharose purification; (ii) nanodisc reconstitution; (iii) size exclusion chromatography; and (iv) Strep-tactin purification. (a) Size exclusion chromatography profile of the OpuA-H and OpuA-HS nanodiscs. Star represents the peak fraction used for further studies. (b) Coomassie-stained 12.5\% SDS-PAGE samples of the different stages of the purification process. The fractions tested were flow through (FT), wash (W), elution (E), and the peak fraction containing nanodiscs (N). Note that OpuABC-H and OpuABC-SS subunits can be distinguished by their different migration in 12.5\% SDS-PAGE gels. (c) ATPase activity in the presence (black bar) and absence (white bar) of $62 \mu \mathrm{M}$ glycine-betaine. Error bars represent the standard deviation of independent triplicates.

\section{Discussion}

One of the crucial steps in the in vivo formation of heterodimers is the synthesis of the two subunits in comparable amounts and their encounter at the appropriate time; that is, the formation of heterodimers should be competitive with the formation of "unwanted" homodimers. When aiming to turn a homodimeric protein into a heterodimeric complex, it is important to know which factors influence this process to tweak the dimerization in favor of heterodimer formation. Moreover, a deeper understanding of the mechanisms of (membrane) protein multimerization is important from a general scientific point of view.

Spatial separation of the sites of protein synthesis may be a key factor in the multimerization of proteins. For luciferase in E. coli, it has been shown that the efficiency of dimerization of its subunits (LuxA and LuxB) decreases when transcribed from distant chromosomal sites [12]. In a different study [38], Shiber and colleagues found that nine out of 12 hetero-oligomeric protein complexes in Saccharomyces cerevisiae assemble 
co-translationally, and the other three make use of chaperones, illustrating that assembly of oligomers is a complex process.

Membrane proteins have a lower lateral mobility than cytoplasmic proteins $[39,40]$ and are restricted to a two-dimensional space. It is very well possible that the dimerization of membrane proteins has an even stronger dependence on the location of synthesis. The self-association of proteins in membranes is enhanced by their orientational restriction and volume exclusion as a result of the macromolecular crowding in the membrane [14]. When the genes for heteromeric complexes are not present in a single operon, it is likely that the local concentration of the identical protomers (produced from one transcript) is higher than that of dissimilar protomers (produced from different transcripts). Thus, the chance of two proteins to assemble into a complex will be higher when synthesized from a single transcript and polysomes docked onto vicinal Sec translocons than when the proteins are produced from distant transcripts. With this reasoning, we would expect to find less heterodimeric OpuA, because OpuABC-H and OpuABC-SS are synthesized from different transcripts. Indeed, we see that most of the protein is lost during the two-step purification, even after optimizing the process. This can indicate that there is room for improvement in the purification protocol, but we believe that the data hint at the presence of large amounts of homodimeric protein. Yet, we do find amounts of heterodimeric OpuA that are sufficient for follow-up studies. It is possible that the high expression levels of OpuA increased the chance for OpuABC-H and OpuABC-SS to find each other even when they are introduced into the membrane at distant sites.

The assembly of multimeric proteins is highly dependent on the proximity of their subunits. Once the folding of the protein chains begins, assembly can already occur between interface residues, increasing the risk of mis-assembly if the folding was still partial or defective. Therefore, many homomeric proteins are enriched for protein contacts toward their C-terminus, decreasing the tendency of premature assembly [41]. We reason that provided a structure is available, the formation of heterodimers can be enhanced by modification of the interaction region to create a complementary contact interface that favours heterodimer formation and prevents homodimerization. Alternatively, expressing the protomers in close proximity (perhaps on the same mRNA) to increase their local concentration could enhance the heterodimer formation.

While other factors can influence the formation of heterodimers theoretically, we have shown that a simple systematic approach involving the selection of the appropriate affinity tag and varying the temperature and production conditions can already significantly increase the heterodimer yield. As the overproduction of membrane proteins induces stress (vide supra), we reasoned that lowering the temperature may reduce the amount of protein and the amount of stress. We find the best conditions to be growth at $30^{\circ} \mathrm{C}$ and a slow induction at $21^{\circ} \mathrm{C}$ for a period of $4 \mathrm{~h}$.

Even though there is a wealth of information left to uncover on the formation of (hetero)multimeric proteins, we have paved the path to in vivo heterodimer formation out of a homodimeric protein and present an efficient way of purifying the formed heterodimers. The approach is feasible with relatively unstable proteins as the complexes are stabilized in the lipid environment of nanodiscs, i.e., after the first purification step. Further research may lead to improvements in the ratio of hetero- over homodimers and open the gate to the elucidation of complex formation in vivo.

\section{Materials and Methods}

\subsection{Materials}

Common chemicals were ordered from Merck (Darmstadt, Germany) The pMSP1D1 plasmid was purchased from Addgene (Watertown, MA, USA) [20061]. The lipids 1,2-dioleoyl-sn-glycero-3- phosphatidylcholine (DOPC) [850375C], 1,2-dioleoyl-snglycero-3-phos- phatidylethanolamine (DOPE) [850725C], and 1,2-dioleoyl-sn-glycero-3phosphatidylglycerol (DOPG) [840475C] were purchased from Avanti Polar Lipids, Inc (Al- 
abaster, AL, USA) (>99\% pure, in chloroform). n-dodecyl- $\beta$-Dmaltoside (DDM) [D97002] was purchased from Glycon Biochemicals GmbH (Luckenwalde, Germany).

\subsection{Construction of Strains and Growth Conditions}

The bacterial strains, plasmids, and primers used in the present study are listed in Table 1. Plasmids were propagated in Lactococcus lactis strain Opu401 [26] (which is L. lactis NZ9000 with the opuA genes deleted). To construct the OpuA StrepII-tagged homodimer, the $p N i s A$ promoter [41] and the opuABC and opuAA genes were PCR-amplified from pNZopuAHis [26] with primers 6428 and 6429. The backbone of the pIL253 vector [24] was amplified with primers 6430 and 6431, which contained the StrepII-tag sequence. The two amplified fragments were ligated to create the pILopuAS vector. The OpuA TwinStrepIItagged homodimer was constructed using the pILopuAS vector as a template, where the StrepII-tag polypeptide sequence (SA-WSHPQFEK) was exchanged for the TwinStrepIItag (WSHPQFEKGGGSGGGSGGS-SAWSHPQFEK), yielding the pILopuASS vector. As a result, the three vectors contained the opuAA and opuABC genes under the control of the nisin-inducible $p N i s A$ promoter (the original operon structure was retained, except that the native opuA promoter was replaced by $p N i s A$ ), and the recombinant genes produce proteins with an affinity tag at the $\mathrm{C}$-terminus of the OpuABC subunit. The strains producing the heterodimeric OpuA carry two possible combinations of plasmids: pNZopuAHis with pILopuAS or pNZopuAHis with pILopuASS. To construct the recA deletion strain L. lactis $401 \Delta r e c A$, the flanking regions of $r e c A$ were amplified using primers 7036 and 7037 . The pCS1966 vector [42] was amplified with primers 7038 and 7039. These two fragments were ligated, obtaining the pCS1966-RecA vector. The pCS1966 derivative was obtained and maintained in Escherichia coli K-12 strain MG1655 [43]. The pCS1966-RecA vector was introduced in L. lactis 401 cells, and positive colonies were selected in SA medium plates [44] supplemented with $20 \mu \mathrm{g} / \mathrm{mL}$ 5-fluoroorotic acid hydrate. The double knockout strain $(\triangle o p u A, \Delta r e c A)$ was named L. lactis $401 \Delta r e c A$.

Table 1. Strains, plasmids, and oligonucleotides used in the present study.

\begin{tabular}{cc}
\hline Strain & Reference \\
\hline L. lactis Opu401 & {$[26]$} \\
L. lactis NZ9700 & {$[45]$} \\
L. lactis $401 \Delta$ rec $A$ & This work \\
E. coli MG1655 & {$[43]$} \\
\hline Plasmid & Reference \\
pNZopuAHis & {$[26]$} \\
pILOpuAS & This work \\
pILOpuASS & This work \\
pCS1966 & {$[42]$} \\
pCS1966-RecA & This work \\
pIL253 & {$[24]$} \\
pMSP1D1 & Addgene \\
\hline Oligonucleotide & Sequence \\
\hline 6494 & AAACTGCGGAUGAGACCAAGCAGAACGACCCTCAATGGATCC \\
6493 & AGCTCCAAGAUCTAGTCTTATAAC \\
6429 & ATCCGCAGTTUGAAAAATAATAATTGGATTAGTTCTTGTGGTTACG \\
6430 & ATCTTGGAGCUTCCATGTAATCGGGTTCTTC \\
6431 & AATCAATCAUGAACCTGCTCCTC \\
7288 & ATGATTGATUGGATTAGTTCTTGTGTTACG \\
7234 & AATTCCCAAGUTAGTCATTCTGACTG \\
\hline
\end{tabular}


Table 1. Cont.

\begin{tabular}{cc}
\hline Oligonucleotide & Sequence \\
\hline 7233 & ACTTGGGAATUCGTCAAGTTTCAACGGAATTAG \\
7038 & AGGCTACACTAGUTCTAGAGCG \\
7039 & AGGTTGTCCACUCGGTACCCAG \\
7037 & ACTAGTGTAGCCUTCAAGATCCTAGTCAGCATTCC \\
7036 & AGTGGACAACCUATAGAAGCCACTTATCCAAG \\
\hline
\end{tabular}

All the constructs were engineered by the ligation-free uracil-excision based-technique USER cloning method [46]. The PCR amplifications were carried out by the PfuX7 DNA polymerase [47] with uracil-containing primers, and the amplified fragments were ligated with USER enzyme (New England Biolabs, Inc, Ipswich, MA, USA). Plasmid DNA was isolated using the Macherey-Nagel NucleoSpin Plasmid QuickPure Kit (Thermo Fisher Scientific, Groningen, The Netherlands). DNA clean-up was performed with the MachereyNagel NucleoSpin Gel and PCR Clean-up Kit (Thermo Fisher Scientific, Groningen, The Netherlands). Constructs were checked by PCR amplification and subsequent sequencing analysis by Eurofins Scientific (Heerenveen, The Netherlands). The strains were routinely cultivated semi-anaerobically at $30^{\circ} \mathrm{C}$ in M17 broth (Oxoid, Wesel, Germany) supplemented with 1\% $(w / v)$ glucose (Merck, Darmstadt, Germany). When needed, the media were supplemented with $5 \mu \mathrm{g} / \mathrm{mL}$ of erythromycin and/or chloramphenicol.

\subsection{Expression of OpuABC Genes}

L. lactis OpuA-producing strains were grown in 2 or $10 \mathrm{~L} \mathrm{pH-controlled} \mathrm{bioreactors.}$ Cells were propagated in M17 broth supplemented with $1 \%(w / v)$ glucose plus $5 \mu \mathrm{g} / \mathrm{mL}$ of the appropriate antibiotic at $30^{\circ} \mathrm{C}$ with stirring $(200 \mathrm{rpm})$. A constant $\mathrm{pH}$ of 6.5 was kept by titrating the culture with $4 \mathrm{M} \mathrm{KOH}$. Unless specified otherwise, cultures were induced at an $\mathrm{OD}_{600}$ of 2 with $0.05 \%(\mathrm{v} / \mathrm{v})$ of nisin $\mathrm{A}^{*}$ (culture supernatant of the nisin A producing strain L. lactis NZ9700 [36]) to initiate the transcription from the NisA promoter and the addition of extra $1 \%(w / v)$ glucose to obtain higher growth yields. To promote heterodimer formation, the temperature of the culture was decreased to $21^{\circ} \mathrm{C}$, during the induction, by cooling the bioreactor with ice-cold water, simultaneously with addition of the inducer. The decrease of temperature from 30 to $21^{\circ} \mathrm{C}$ took approximately $15 \mathrm{~min}$. Cells were harvested by centrifugation ( $15 \mathrm{~min}, 6,000 \times \mathrm{g}, 4^{\circ} \mathrm{C}$ ) after $2 \mathrm{~h}$ of induction, washed twice, and resuspended to an $\mathrm{OD}_{600}$ of 100 in ice-cold $50 \mathrm{mM} \mathrm{KPi} \mathrm{pH} 7.5$ buffer, flash-frozen, and stored at $-80^{\circ} \mathrm{C}$.

\subsection{Optimization of the Induction Conditions}

To promote the heterodimer formation in the cell, different induction conditions were tested; that is, nisin $\mathrm{A}^{*}$ concentration, the post-induction temperature, and induction time were varied. For this purpose, L. lactis Opu401, carrying pNZopuAHis and pILopuAS, was grown in a $2 \mathrm{~L}$ flask containing M17 broth supplemented with $1 \%(w / v)$ glucose, $5 \mu \mathrm{g} / \mathrm{mL}$ erythromycin, plus $5 \mu \mathrm{g} / \mathrm{mL}$ chloramphenicol at $30{ }^{\circ} \mathrm{C}$ with stirring (200 rpm). When the culture reached an $\mathrm{OD}_{600}$ of 0.5 , it was divided into smaller cultures of $50 \mathrm{~mL}$ each and induced with $0.05 \%, 0.02 \%, 0.01 \%$ or $0.002 \%(v / v)$ of nisin $A^{*}$. Then, the cultures were incubated at $21{ }^{\circ} \mathrm{C}$ or $30^{\circ} \mathrm{C}$ for induction times varying from 2 to $8 \mathrm{~h}$. Cells were harvested by centrifugation $\left(15 \mathrm{~min}, 6000 \times g, 4^{\circ} \mathrm{C}\right)$, washed twice, and resuspended to an $\mathrm{OD}_{600}$ of 34 in ice-cold $50 \mathrm{mM} \mathrm{KPi}$, pH 7.5. Samples of $1.5 \mathrm{~mL}$ were mixed with $400 \mathrm{mg}$ of $0.1 \mathrm{~mm}$ glass beads (Merck, Darmstadt, Germany) and lysed with a TissueLyser LT (Qiagen, Hilden, Germany) for $5 \mathrm{~min}$ at high speed. Glass beads and cellular debris were removed by centrifugation $\left(15 \mathrm{~min}, 25,000 \mathrm{xg}, 4^{\circ} \mathrm{C}\right)$. Pellets were discarded, and membrane vesicles were collected by centrifugation $\left(20 \mathrm{~min}, 267,000 \times g, 4^{\circ} \mathrm{C}\right.$ ) and resuspended in $1.8 \mathrm{~mL}$ of ice-cold $50 \mathrm{mM} \mathrm{Kpi} \mathrm{pH} 7.5$ supplemented with $20 \%(v / v)$ glycerol. Then, membrane vesicles were solubilized with $0.5 \%(w / v)$ DDM and nutated for $2 \mathrm{~h}$ at $4{ }^{\circ} \mathrm{C}$, after which $\mathrm{Ni}^{2+}$. 
Sepharose purification was carried out as described below. The presence of the heterodimer was analyzed by immunoblotting the elution samples with antibodies against StrepII-tag.

\subsection{Isolation and Preparation of Membrane Vesicles}

The isolation and preparation of membrane vesicles were performed as described in [48] with minor changes. Cell pellets were thawed on ice and supplemented with $2 \mathrm{mM} \mathrm{MgSO}_{4}$ plus $100 \mu \mathrm{g} / \mathrm{mL}$ DNAse. Cells were lysed by double passage through a cell disruptor (Constant Systems Ltd., Daventry, UK) at 39,000 Psi. After lysis, 1 mM PMSF plus 0.05 M EDTA ( $\mathrm{pH}$ 8.0) were immediately added to avoid protein degradation. The cell debris was removed by centrifugation $\left(15 \mathrm{~min}, 12,000 \times g, 4{ }^{\circ} \mathrm{C}\right)$, and the membrane vesicles were collected by ultracentrifugation $\left(1 \mathrm{~h}, 267,000 \times g, 4{ }^{\circ} \mathrm{C}\right)$ and resuspended in ice-cold buffer A (50 mM KPi, pH 7.5, $20 \%(v / v)$ glycerol). Aliquots were flash frozen and stored at $-80^{\circ} \mathrm{C}$. The protein concentration was determined using the Pierce BCA Protein Assay Kit (Thermo Fisher Scientific, Groningen, The Netherlands).

\subsection{Purification of OpuA}

The purification process of OpuA was divided in a series of steps, of which the order was determined by the type and number of affinity tags of the final construct. Hence, the homodimeric forms of OpuA were subjected to a single affinity purification depending on the affinity tag, that are Nickel-Sepharose or Strep-tactin purification, followed by reconstitution in nanodiscs and size exclusion chromatography on a Superdex 200 increase 10/300 GL column. However, the heterodimeric forms of OpuA required a two-step purification process that could be conducted in different order as described in the Results section. Below, we independently describe all the required steps for the purification of any of the OpuA constructs but note that the order may vary for each of them. For the solubilization of membrane vesicles, prior to $\mathrm{Ni}^{2+}$-Sepharose affinity purification, membrane vesicles were quickly thawed and diluted to a final protein concentration of $5 \mathrm{mg} / \mathrm{mL}$ in $50 \mathrm{mM} \mathrm{KPi} \mathrm{pH} \mathrm{7.0,} 200 \mathrm{mM} \mathrm{KCl,} \mathrm{20 \%} \mathrm{(v/v)} \mathrm{glycerol} \mathrm{plus} 10 \mathrm{mM}$ imidazole. When Strep-tagged protein samples were to be purified, membrane vesicles were harvested (20 min, 267,000 $\times \mathrm{g}, 4^{\circ} \mathrm{C}$ ) and pellets were dissolved in $50 \mathrm{mM}$ Tris- $\mathrm{HCl} \mathrm{pH} \mathrm{8.0,150} \mathrm{mM}$ $\mathrm{NaCl}$ plus $20 \%(\mathrm{v} / \mathrm{v})$ glycerol at a protein concentration of $5 \mathrm{mg} / \mathrm{mL}$. Then, membrane vesicles were solubilized with $0.5 \%(w / v)$ DDM and nutated for $1 \mathrm{~h}$ at $4{ }^{\circ} \mathrm{C}$. Supernatant was collected by ultracentrifugation $\left(20 \mathrm{~min}, 267,000 \times g, 4{ }^{\circ} \mathrm{C}\right)$.

\section{7. $\mathrm{Ni}^{2+}$-Sepharose Affinity Purification of His-Tagged Proteins}

$\mathrm{Ni}^{2+}$-Sepharose resin (GE Healthcare, Hoevelaken, The Netherlands) $(0.5 \mathrm{~mL}$ of resin per $10 \mathrm{mg}$ total protein) was pre-equilibrated with 12 column volumes (CV) of distilled water followed by $4 \mathrm{CV}$ of wash buffer (50 mM KPi pH 7.0, $200 \mathrm{mM} \mathrm{KCl,} \mathrm{0.02 \%} \mathrm{(w/v)} \mathrm{DDM}$ plus 20\% (v/v) glycerol) supplemented with $10 \mathrm{mM}$ imidazole ( $\mathrm{pH} 7.5)$. To decrease the detergent concentration, solubilized membrane vesicles were diluted five-fold in ice-cold buffer (50 mM KPi pH 7.0, $200 \mathrm{mM} \mathrm{KCl,} \mathrm{20 \%} \mathrm{(v/v)} \mathrm{glycerol} \mathrm{plus} 10 \mathrm{mM}$ imidazole) and then incubated with the $\mathrm{Ni}^{2+}$-Sepharose resin under rotation for $2 \mathrm{~h}$ at $4{ }^{\circ} \mathrm{C}$. The mixture was poured into a column, and the resin was washed with $20 \mathrm{CV}$ of wash buffer supplemented with $50 \mathrm{mM}$ imidazole. Proteins were eluted with $2.5 \mathrm{CV}$ of wash buffer supplemented with $500 \mathrm{mM}$ imidazole. Protein concentration in the elution fractions was determined by absorbance measurements at $280 \mathrm{~nm}$.

\subsection{Reconstitution in Lipid Bilayer Nanodiscs}

Reconstitution was performed as described previously [27] with some modifications. Synthetic lipids were mixed in a ratio of $50 \mathrm{~mol} \%$ DOPE, $12 \mathrm{~mol} \%$ DOPC and $38 \mathrm{~mol} \%$ DOPG, and the preformed liposomes were prepared as described by [49]. Then, the mixture was extruded 13 times through a $400 \mathrm{~nm}$ polycarbonate filter (Avestin Europe $\mathrm{GmbH}$, Mannheim, Germany) to obtain large unilamellar vesicles and then solubilized with $12 \mathrm{mM}$ DDM followed by heavy vortexing. The standard procedure for the reconstitution of OpuA 
in nanodiscs was at an OpuA/MSP1D1/liposomes ratio of 1:20:2000 (w/w), respectively, in a final volume of $700 \mu \mathrm{L}$ giving the following composition: $50 \mathrm{mM} \mathrm{KPi} \mathrm{pH} \mathrm{7.0,12} \mathrm{mM}$ DDM, $4 \%(v / v)$ glycerol, $0.72 \mu \mathrm{M}$ OpuA, $14.3 \mu \mathrm{M}$ MSP1D1 plus $1.43 \mathrm{mM}$ lipid. To optimize the method, we tested an OpuA/MSP1D1/lipid ratio of 1:20:1000 $(w / w)$, starting with a 6 times higher concentration of OpuA, having a final composition of $50 \mathrm{mM} \mathrm{KPi} \mathrm{pH} \mathrm{7.0,}$ $12 \mathrm{mM}$ DDM, 4\% (v/v) glycerol, $4.32 \mu \mathrm{M}$ OpuA, $85.8 \mu \mathrm{M}$ MSP1D1 plus $4.29 \mathrm{mM}$ lipid. When needed, OpuA samples were concentrated in $0.5 \mathrm{~mL} \mathrm{30,000} \mathrm{kDa} \mathrm{concentrators} \mathrm{(Vivaspin).}$ The reconstitution mixture was nutated for $1 \mathrm{~h}$ at $4{ }^{\circ} \mathrm{C}$, after which detergent was removed by adding $500 \mathrm{mg}$ of SM2 Biobeads and incubating overnight at $4{ }^{\circ} \mathrm{C}$ with gentle agitation. Biobeads and protein aggregates were carefully removed by transferring the sample with a syringe to a new Eppendorf tube and subsequent centrifugation $(25,000 \times g, 10 \mathrm{~min}$, $4{ }^{\circ} \mathrm{C}$ ). Then, the mixture was fractionated by size exclusion chromatography (SEC), using a Superdex 200 Increase 10/300 GL column (GE Healthcare, Hoevelaken, The Netherlands) equilibrated with 50mM KPi pH 7.0 supplemented with $200 \mathrm{mM} \mathrm{KCl}$. Protein-containing fractions were pooled and stored at $4{ }^{\circ} \mathrm{C}$ until further use.

\subsection{Purification of Strep-Sagged OpuA Proteins}

Strep-tactin superflow high-capacity resin (IBA LifeSciences, Göttingen, Alemania) $(1 \mathrm{~mL}$ resin per $10 \mathrm{mg} / \mathrm{mL}$ protein) was pre-equilibrated with $4 \mathrm{CV}$ of buffer $\mathrm{W} 1(50 \mathrm{mM}$ Tris- $\mathrm{HCl} \mathrm{pH}$ 8.0, $150 \mathrm{mM} \mathrm{NaCl}$ supplemented with $20 \%(v / v)$ glycerol plus $0.02 \%(w / v)$ $\mathrm{DDM}$, for membrane vesicles samples) or with buffer W2 (50 mM Tris-HCl pH 8.0, $150 \mathrm{mM}$ $\mathrm{NaCl}$ supplemented with $4 \%(v / v)$ glycerol, for samples containing OpuA nanodiscs). Samples were incubated with the pre-equilibrated resin and nutated for $1 \mathrm{~h}$ at $4{ }^{\circ} \mathrm{C}$. The flow through was slowly passed twice through the column by gravity, and then, the column was washed 5 times with $3 \mathrm{CV}$ of buffer W1 or W2. Proteins were eluted with $0.5 \mathrm{CV}$ of buffer W1 or W2, both supplemented with $10 \mathrm{mM}$ of d-Desthiobiotin. After $5 \mathrm{~min}$ of incubation, the elution was collected, and the procedure was repeated 4 times more. Protein concentration was determined in the elution fractions by absorbance measurements at $280 \mathrm{~nm}$.

\subsection{SDS-PAGE and Western Blotting Analysis}

Samples from all the steps of the purification process were collected and analyzed by SDS-PAGE using $12.5 \%$ poly-acrylamide gels. Pictures of the Coomassie-stained gels were taken by a Fujifilm LAS 3000 Imaging system (Fujifilm, Düsseldorf, Germany). To confirm correct subunit composition, Western blot analyses were carried out. Samples were resolved in a $12.5 \%$ SDS-PAGE and transferred to a PVDF membrane with primary antibodies against StrepII-tag or $\mathrm{His}_{6}$-tag (Qiagen, Hilden, Germany). Transfer of the proteins was done in $40 \mathrm{~min}$ at $0.08 \mathrm{~A}$ in a Trans-Blot SD Semi-Dry Transfer system (BioRad, Nazareth, Belgium). Proteins were visualized by inducing chemiluminescence with the CDP-star kit (tropix, inc., London, UK) in the LAS-3000 imaging system.

\subsection{ATPase Activity Assay}

The ATPase activity of OpuA reconstituted in nanodiscs was analyzed using a coupled enzyme assay as described previously $[27,50]$. In brief, the measurements were performed at $30^{\circ} \mathrm{C}$ in a 96-well plate using a Spark $10 \mathrm{M}$ 96-well plate reader (Tecan, Männedorf, Suiza). A standard measurement solution of $200 \mu \mathrm{L}$ per well contained $50 \mathrm{mM} \mathrm{KPi} \mathrm{(pH} \mathrm{7.0),}$ $0.3 \mathrm{M} \mathrm{KCl}, 57 \mathrm{nM}$ OpuA reconstituted in nanodiscs, $4 \mathrm{mM}$ sodium phosphoenolpyruvate, $0.3 \mathrm{mM} \mathrm{NADH}$, and $3.5 \mu \mathrm{L}$ of pyruvate kinase/lactic dehydrogenase enzyme mixture from rabbit muscle in $50 \%$ glycerol, with or without $62 \mu \mathrm{M}$ substrate (glycine betaine). After incubation for $3 \mathrm{~min}$ at $30^{\circ} \mathrm{C}, 10 \mathrm{mM} \mathrm{MgATP} \mathrm{pH} 7.0$ was added to each well, and the absorbance of NADH at $340 \mathrm{~nm}$ was monitored over a period of $15 \mathrm{~min}$. The oxidation of NADH is stoichiometrically coupled to the amount of ATP consumed, and the ATPase activity was expressed as the moles of ATP hydrolyzed per min per mg of OpuA. 
Author Contributions: B.P., P.A.-S. and H.R.S. designed the research; P.A.-S. and H.R.S. performed the research; B.P., P.A.-S. and H.R.S. analyzed data; B.P., P.A.-S. and H.R.S. wrote the manuscript. All authors have read and agreed to the published version of the manuscript.

Funding: This research was funded by an ERC Advanced Grant (ABCvolume; \#670578).

Data Availability Statement: All data needed to evaluate the conclusions in the paper are present in the paper. All data and materials used in the analysis are available upon request to the lead author.

Acknowledgments: We thank Marco van den Noort for critical reading of the manuscript and Gea Schuurman-Wolters for fruitful discussions.

Conflicts of Interest: The authors declare no conflict of interest.

\section{References}

1. Lynch, M. The evolution of multimeric protein assemblages. Mol. Biol. Evol. 2012, 29, 1353-1366. [CrossRef]

2. Marsh, J.A.; Rees, H.A.; Ahnert, S.E.; Teichmann, S.A. Structural and evolutionary versatility in protein complexes with uneven stoichiometry. Nat. Commun. 2015, 6, 6394. [CrossRef]

3. Goodsell, D.S.; Olson, A.J. Structural symmetry and protein function. Annu. Rev. Biophys. Biomol. Struct. 2000, 29, 105-153. [CrossRef] [PubMed]

4. Marianayagam, N.J.; Sunde, M.; Matthews, J.M. The power of two: Protein dimerization in biology. Trends. Biochem. Sci. 2004, 29, 618-625. [CrossRef] [PubMed]

5. Hashimoto, K.; Nishi, H.; Bryant, S.; Panchenko, A.R. Caught in self-interaction: Evolutionary and functional mechanisms of protein homooligomerization. Phys. Biol. 2011, 8, 035007. [CrossRef]

6. Forrest, L.R. Structural symmetry in membrane proteins. Annu. Rev. Biophys. 2015, 44, 311-337. [CrossRef] [PubMed]

7. Meng, G.; Fronzes, R.; Chandran, V.; Remaut, H.; Waksman, G. Protein oligomerization in the bacterial outer membrane (Review). Mol. Membr. Biol. 2009, 26, 136-145. [CrossRef] [PubMed]

8. Dalbey, R.E.; Wang, P.; Kuhn, A. Assembly of bacterial inner membrane proteins. Annu. Rev. Biochem. 2011, 80, 161-187. [CrossRef]

9. Fairweather, S.J.; Shah, N.; Bröer, S. Heteromeric solute carriers: Function, structure, pathology and pharmacology. Adv. Exp. Med. Biol. 2021, 21, 13-127.

10. Wells, J.N.; Bergendahl, L.T.; Marsh, J.A. Co-translational assembly of protein complexes. Biochem. Soc. Trans. 2015, 43, 1221-1226. [CrossRef]

11. Wells, J.N.; Bergendahl, L.T.; Marsh, J.A. Operon gene order is optimized for ordered protein complex assembly. Cell Rep. 2016, 14, 679-685. [CrossRef] [PubMed]

12. Shieh, Y.W.; Minguez, P.; Bork, P.; Auburger, J.J.; Guilbride, D.L.; Kramer, G.; Bukau, B. Operon structure and cotranslational subunit association direct protein assembly in bacteria. Science 2015, 350, 678-680. [CrossRef]

13. Natan, E.; Wells, J.N.; Teichmann, S.A.; Marsh, J.A. Regulation, evolution and consequences of cotranslational protein complex assembly. Curr. Opin. Struct. Biol. 2017, 42, 90-97. [CrossRef]

14. Grasberger, B.; Minton, A.P.; DeLisi, C.; Metzger, H. Interaction between proteins localized in membranes. Proc. Natl. Acad. Sci. USA 1986, 83, 6258-6262. [CrossRef]

15. Skach, W.R. Cellular mechanisms of membrane protein folding. Nat. Struct. Mol. Biol. 2009, 16, 606-612. [CrossRef] [PubMed]

16. Nanda, J.S.; Lorsch, J.R. Labeling of a protein with fluorophores using maleimide derivitization. Methods Enzymol. 2014, 536, 79-86.

17. Dobson, C.M. Biophysical techniques in structural biology. Annu. Rev. Biochem. 2019, 88, 25-33. [CrossRef]

18. Biemans-Oldehinkel, E.; Poolman, B. On the role of the two extracytoplasmic substrate-binding domains in the ABC transporter OpuA. EMBO J. 2003, 22, 5983-5993. [CrossRef] [PubMed]

19. Becker, M.; Maximov, S.; Becker, M.; Meyer, U.; Wittmann, A.; Krämer, R. Analysis of putative protomer crosstalk in the trimeric transporter BetP: The heterotrimer approach. Biochim. Biophys. Acta 2014, 1837, 888-898. [CrossRef]

20. Riederer, E.A.; Focke, P.J.; Georgieva, E.R.; Akyuz, N.; Matulef, K.; Borbat, P.P.; Freed, J.H.; Blanchard, S.C.; Boudker, O.; Valiyaveetil, F.I. A facile approach for the in vitro assembly of multimeric membrane transport proteins. eLife 2018, 7, e36478. [CrossRef]

21. Ritchie, T.K.; Grinkova, Y.V.; Bayburt, T.H.; Denisov, I.G.; Zolnerciks, J.K.; Atkins, W.M.; Sligar, S.G. Reconstitution of membrane proteins in phospholipid bilayer nanodiscs. Methods Enzymol. 2009, 464, 211-231. [PubMed]

22. Bayburt, T.H.; Sligar, S.G. Membrane protein assembly into nanodiscs. FEBS Lett. 2010, 584, 1721-1727. [CrossRef]

23. Vos, W.M. Gene cloning and expression in lactic streptococci. FEMS Microbiol. Lett. 1987, 46, 281-295. [CrossRef]

24. Simon, D.; Chopin, A. Construction of a vector plasmid family and its use for molecular cloning in Streptococcus lactis. Biochimie 1988, 70, 559-566. [CrossRef]

25. Montalbán-López, M.; Deng, J.; van Heel, A.J.; Kuipers, O.P. Specificity and application of the lantibiotic protease NisP. Front. Microbiol. 2018, 9, 160. [CrossRef] 
26. Biemans-Oldehinkel, E.; Mahmood, N.A.B.N.; Poolman, B. A sensor for intracellular ionic strength. Proc. Natl. Acad. Sci. USA 2006, 103, 10624-10629. [CrossRef] [PubMed]

27. Karasawa, A.; Swier, L.J.Y.M.; Stuart, M.C.A.; Brouwers, J.; Helms, B.; Poolman, B. Physicochemical factors controlling the activity and energy coupling of an ionic strength-gated ATP-Binding Cassette (ABC) transporter. J. Biol. Chem. 2013, $288,29862-29871$. [CrossRef]

28. Van der Heide, T.; Poolman, B. Osmoregulated ABC-transport system of Lactococcus lactis senses water stress via changes in the physical state of the membrane. Proc. Natl. Acad. Sci. USA 2000, 97, 7102-7106. [CrossRef]

29. Duwat, P.; Ehrlich, S.D.; Gruss, A. The recA gene of Lactococcus lactis: Characterization and involvement in oxidative and thermal stress. Mol. Microbiol. 1995, 17, 1121-1131. [CrossRef]

30. Roca, A.I.; Cox, M.M. RecA protein: Structure, function, and role in recombinational DNA repair. Prog. Nucleic. Acid. Res. Mol. Biol. 1997, 56, 129-223.

31. Sanders, J.W.; Venema, G.; Kok, J. Environmental stress responses in Lactococcus lactis. FEMS Microbiol. Rev. 1999, $23,483-501$. [CrossRef]

32. Mierau, I.; Olieman, K.; Mond, J.; Smid, E.J. Optimization of the Lactococcus lactis nisin-controlled gene expression system NICE for industrial applications. Microb. Cell Fact. 2005, 4, 16. [CrossRef] [PubMed]

33. Hoffmann, F.; Rinas, U. Stress induced by recombinant protein production in Escherichia Coli. Adv. Biochem. Eng. Biotechnol. 2004, 89, 73-92. [PubMed]

34. Schweder, T.; Hecker, M. Monitoring of stress responses. Physiol. Stress Responses Bioprocesses 2004, 89, 47-71.

35. Zweers, J.C.; Wiegert, T.; Van Dijl, J.M. Stress-responsive systems set specific limits to the overproduction of membrane proteins in Bacillus subtilis. Appl. Environ. Microbiol. 2009, 75, 7356-7364. [CrossRef] [PubMed]

36. Kuipers, O.P.; de Ruyter, P.G.G.A.; Kleerebezem, M.; de Vos, W.M. Quorum sensing-controlled gene expression in lactic acid bacteria. J. Biotechnol. 1998, 64, 15-21. [CrossRef]

37. Sikkema, H.R.; van den Noort, M.; Rheinberger, J.; de Boer, M.; Krepel, S.T.; Schuurman-Wolters, G.K.; Paulino, C.; Poolman, B. Gating by ionic strength and safety check by cyclic-di-AMP in the ABC transporter OpuA. Sci. Adv. 2020, 6, eabd7697. [CrossRef] [PubMed]

38. Shiber, A.; Döring, K.; Friedrich, U.; Klann, K.; Merker, D.; Zedan, M.; Tippmann, F.; Kramer, G.; Bukau, B. Cotranslational assembly of protein complexes in eukaryotes revealed by ribosome profiling. Nature 2018, 561, 268-272. [CrossRef]

39. Ramadurai, S.; Duurkens, R.; Krasnikov, V.V.; Poolman, B. Lateral diffusion of membrane proteins: Consequences of hydrophobic mismatch and lipid composition. Biophys. J. 2010, 99, 1482-1489. [CrossRef]

40. Schavemaker, P.E.; Boersma, A.J.; Poolman, B. How important is protein diffusion in prokaryotes? Front. Mol. Biosci. 2018, 5, 93. [CrossRef]

41. Natan, E.; Endoh, T.; Haim-Vilmovsky, L.; Flock, T.; Chalancon, G.; Hopper, J.T.S.; Kintses, B.; Horvath, P.; Daruka, L.; Fekete, G.; et al. Cotranslational protein assembly imposes evolutionary constraints on homomeric proteins. Nat. Struct. Mol. Biol. 2018, 25, 279-288. [CrossRef] [PubMed]

42. Solem, C.; Defoor, E.; Jensen, P.R.; Martinussen, J. Plasmid PCS1966, a new selection/counterselection tool for lactic acid bacterium strain construction based on the oroP gene, encoding an orotate transporter from Lactococcus lactis. Appl. Environ. Microbiol. 2008, 74, 4772-4775. [CrossRef]

43. Jensen, K.F. The Escherichia coli K-12 “wild types" W3110 and MG1655 have an rph frameshift mutation that leads to pyrimidine starvation due to low pyrE expression levels. J. Bacteriol. 1993, 175, 3401-3407. [CrossRef] [PubMed]

44. Jensen, P.R.; Hammer, K. Minimal requirements for exponential growth of Lactococcus lactis. Appl. Environ. Microbiol. 1993, 59, 4363-4366. [CrossRef] [PubMed]

45. De Ruyter, P.G.G.A.; Kuipers, O.P.; De Vos, W.M. Controlled gene expression systems for Lactococcus lactis with the food-grade inducer nisin. Appl. Environ. Microbiol. 1996, 62, 3662-3667. [CrossRef] [PubMed]

46. Bitinaite, J.; Rubino, M.; Varma, K.H.; Schildkraut, I.; Vaisvila, R.; Vaiskunaite, R. USER friendly DNA engineering and cloning method by uracil excision. Nucleic Acids Res. 1992, 35, 1992-2002. [CrossRef]

47. Nørholm, M.H.H. A mutant Pfu DNA polymerase designed for advanced uracil-excision DNA engineering. BMC Biotechnol. 2010, 10, 21. [CrossRef] [PubMed]

48. Pols, T.; Sikkema, H.R.; Gaastra, B.F.; Frallicciardi, J.; Śmigiel, W.M.; Singh, S.; Poolman, B. A synthetic metabolic network for physicochemical homeostasis. Nat. Commun. 2019, 10,1-13. [CrossRef]

49. Geertsma, E.R.; Nik Mahmood, N.A.B.; Schuurman-Wolters, G.K.; Poolman, B. Membrane reconstitution of ABC-transporters and assays of translocator function. Nat. Protoc. 2008, 3, 256-266. [CrossRef]

50. Lycklama A Nijeholt, J.A.; Vietrov, R.; Schuurman-Wolters, G.K.; Poolman, B. Energy coupling efficiency in the type-I ABCtransporter GlnPQ. J. Mol. Biol. 2018, 430, 853-866. [CrossRef] 